Thanks are expressed to the patients who co-operated in this study, and to the consultant surgeons, Mr. W. H. Garvie and Dr. D. M. Proctor, in the departments involved in this work. The project was financed by a grant from the North-East of Scotland Regional Hospital Board's Clinical Research Fund.
References

Fahy, A., and Marshall, M. (1969). British fournal of Anaesthesia, 41, 433. Thomas, E. (1963). British fournal of Anaesthesia, 35, 327.

Hannington-Kiff, J. G. (1969). British fournal of Anaesthesia, 41, 401 Tyrrell, M. F., and Feldman, S. A. (1968). British Journal of Anaesthesia,
40,

\title{
Multicentre, Short-term Therapeutic Trial of Disodium Cromoglycate, With and Without Prednisone, in Adults with Asthma*
}

\author{
T. GEBBIE, \\ E. A. HARRIS, \\ T. V. O'DONNELL,
}

British Medical fournal, 1972, 4, 576-580

\section{Summary}

A total of 117 asthmatic patients were studied in a doubleblind, cross-over trial with half-periods of three weeks in which disodium cromoglycate (D.S.C.G.) was compared with an inactive preparation. D.S.C.G. improved spirometric measurements, at a very high level of statistical significance, more than did placebo. The mean advantage of D.S.C.G. was less than $10 \%$ after three weeks. Symptomatic improvement by D.S.C.G. was small though significant; it was not correlated with spirometric improvement. A history of chronic cough was the only clinical characteristic associated with a better-than-average spirometric response to D.S.C.G.

\section{Introduction}

The effects of disodium cromoglycate (D.S.C.G.) on the respiratory manifestations of antigen-antibody reactions, both in animals and in man, have been striking (Altounyan, 1968; Pepys et al., 1968). In contrast the use of D.S.C.G. in the treatment of adult patients with asthma has produced less convincing results (Grant et al., 1967; Kennedy, 1967; Altounyan and Howell, 1969; Gianoutsos and O'Donnell, 1969; Bernstein et al., 1971). In particular, objective evidence of improvement has been poorly related to symptomatic improvement, although in many trials the individual patient's potential capacity for spirometric improvement has not been clearly indicated. On the other hand, there is evidence (Read and Rebuck, 1969) that in patients receiving continuous treatment with a corticosteroid drug, its dose can be reduced when D.S.C.G. is administered.

In the clinical trial reported below the effect of D.S.C.G. was compared with that of an inactive preparation before and after a three-day course of prednisone in adult patients with chronic asthma.

* Report on a trial co-ordinated by the Clinical Trials Committee of the Medical Research Council of New Zealand.

Wellington Hospital, Wellington, New Zealand

T. GEBBIE, M.B., F.R.A.C.P., Physician

Clinical Physiology Department, Green Lane Hospital, Auckland, New Zealand

E. A. HARRIS, M.D., F.R.C.P., Physician-in-Charge

University of Otago, Dunedin, New Zealand

T. V. O'DONNELL, M.D., F.R.C.P., Professor of Medicine

G. F. S. SPEARS, M.SC., DIP.MATH.STATS., Department of Preventive and Social Medicine

\section{G. F. S. SPEARS}

\section{Patients and Methods}

The general criterion for inclusion in the trial was chronic asthma of moderate severity. "Chronic asthma" was defined by clinical and spirometric evidence of wheeze and airways obstruction of fluctuating degree for at least six months. "Moderate severity" demanded evidence that at some time during the three months before the trial the forced expiratory volume in 1 second $\left(\mathrm{FEV}_{1}\right)$ had increased by at least $20 \%$ in response to an adequate dose of isoprenaline, orciprenaline, or salbutamol aerosol. Patients with chronic bronchitis (defined as a productive cough for at least three consecutive months for at least two successive years (Medical Research Council, 1965), were not excluded, but an attempt was made to include a reasonable number of patients who did not give such a history. Previous treatment with D.S.C.G. was no bar to inclusion, provided that no such treatment had been given for at least eight weeks before the trial began. Otherwise, all patients continued to take their usual treatment according to previously established indications throughout the trial. In 58 of the 117 patients selected asthma had been thought to be of such severity that continuing corticosteroid therapy had been prescribed.

\section{DESIGN OF TRIAL}

The trial was preceded by one week during which preliminary history-taking and examination were completed, and in which the procedure was explained to the patients, and spirometric manoeuvres were practised by them.

The trial itself was conducted simultaneously in all eight centres during the six weeks from 1 March to 7 April 1971, just past the peak of the summer season in the South Pacific area. During the first three weeks either $20 \mathrm{mg}$ disodium cromoglycate (D.S.C.G.) or an inactive control substance $(15 \mathrm{mg}$ lactose, $5 \mathrm{mg}$ sodium sulphate) was given by Spinhaler at 07.00 , $12.00,17.00$, and 22.00 hours. During the second three weeks the alternative substance was given at these hours, the order for each patient being randomly determined. The days of the trial will be referred to as D.S.C.G. 1 to 21 and placebo 1 to 21 , irrespective of the order in which the preparations were given. On days D.S.C.G. 10, 11, and 12, and placebo 10,11 , and 12, prednisone was administered (10 $\mathrm{mg}$ given by mouth every eight hours). The patients were not aware of the activity of the preparations they received. Many patients detected a difference between D.S.C.G. and the placebo, but all were told that the purpose of the trial was "to compare two drugs." The observers were not aware of whether D.S.C.G. or the placebo was being taken, but knew that on days 10,11 , and 12 an active steroid drug was being given. 


\section{RECORDING OF INFORMATION}

During the preliminary week the following inquiries and examinations were undertaken: full history and clinical examination; age, height, and weight; chest radiography; haemoglobin concentration, total and differential leucocyte count; sputum examination for purulence and eosinophils; and $\mathrm{FEV}_{1}$ and vital capacity (VC) before and 20 minutes after the inhalation of two carefully supervised puffs of salbutamol aerosol (average total dose $0.2 \mathrm{mg}$ ). The spirometric procedure set out by Cotes (1966) was followed; each recorded VC and FEV 1 was the mean of three technically satisfactory measurements.

During the trial the patients were asked to attend at the same time (between 10.00 and 16.00 hours) on each of days 0,9 , 13,19 , and 21 for each half of the study, making nine visits in all. In making comparisons, day 0 for the first half was also taken as day 0 for the second half. Patients were asked not to use an inhaler for at least six hours before attendance. On each occasion the chest was examined, spirometric measurements were made before and after salbutamol aerosol inhalation, and the patient's own daily record card was checked for completeness.

Each patient was given a record card on which he was asked to enter daily and nightly scores for nasal congestion, wheeze, breathlessness, tightness in the chest, cough, sputum, and number of attacks of asthma (or, during the night, the number of times he was awakened by asthma). Scores were allotted as follows: no symptoms 1 , mild $2-3$, moderate $4-5$, severe 6 , and intolerable 7. For sputum the scores were 1 to 6 for "no sputum" to "more than two eggcupfuls" a day.

\section{Results \\ CLINICAL FEATURES OF PATIENTS}

One hundred and seventeen patients completed the trial, 13 to 17 in each of the eight centres. Three patients withdrew from the trial; one lost interest, another found the travelling too expensive, and a third withdrew when his asthma deteriorated over the first two weeks. He was receiving placebo at that time. Forty-five per cent. were male; one centre produced only $11 \%$ males, but the others agreed well with the overall sex distribution. Twelve per cent. were under 20 years old, $19 \%$ were 20 to $29,32 \%$ were 30 to $39,32 \%$ were 40 to 49 , and $5 \%$ were over 50 years old.

The age of onset of asthma was ascertained in only 88 patients. In 63 of these ( 30 male and 33 female) asthma began during the first 15 years of life, and in only nine (five male and four female) after 30 years of age. Blood eosinophilia greater than $6 \%$ of the white cell count was found in 56 patients. Of 85 patients in whom sputum was available and examined, 22 showed pronounced and 21 showed minor sputum eosinophilia. A personal history of hay fever and/or skin rashes was given by 75 patients, a family history of asthma or allergic conditions by 87 , and of both conditions by 59 . Seventy-two patients gave a history of cough (with or without sputum) between asthmatic attacks. These patients fulfilled the criteria for a diagnosis of associated chronic bronchitis, which is so commonly found in adult asthmatic patients. Sixteen patients had received D.S.C.G. as treatment previously but none within eight weeks of the start of the trial. Abnormalities in the chest radiograph, other than evidence of hyperinflation, were seen in 22 patients; they consisted of increased lung markings or small linear opacities, and no gross changes were reported.

\section{SPIROMETRY}

The statistical significance of the changes in $\mathrm{FEV}_{1}, \mathrm{VC}$, and $\mathrm{FEV}_{1} / \mathrm{VC}$ ratio associated with D.S.C.G. at different stages of the trial are shown in Table $I$. The spirometric data were
TABLE I-Significance of Spirometric Differences between D.S.C.G. and Placebo on Corresponding Days

\begin{tabular}{|c|c|c|c|c|}
\hline Day: & 9 & 13 & 19 & 21 \\
\hline $\begin{array}{l}\text { FEV } \text { (D.S.C.G./ } \\
\text { placebo): } \\
\text { Before salbutamol } \\
\text { After salbutamol }\end{array}$ & $\begin{array}{l}\text { N.S. } \\
\text { N.S. }\end{array}$ & $\begin{array}{l}\text { N.S. } \\
\text { N.S. }\end{array}$ & $\begin{array}{c}0.001<2 \mathrm{P}<0.01 \\
2 \mathrm{P}<0.001\end{array}$ & $\begin{array}{l}2 \mathrm{P}<0.001 \\
2 \mathrm{P}<0.001\end{array}$ \\
\hline $\begin{array}{l}\text { VC (D.S.C.G.I } \\
\text { placebo): } \\
\text { Before salbutamol } \\
\text { After salbutamol }\end{array}$ & $\begin{array}{l}0.01<2 \mathrm{P}<0.02 \\
0.01<2 \mathrm{P}<0.02\end{array}$ & $\begin{array}{l}\text { N.S. } \\
\text { N.S. }\end{array}$ & $\begin{array}{l}0.001<2 \mathrm{P}<0.01 \\
0.02<2 \mathrm{P}<0.05\end{array}$ & $\begin{array}{l}0.001<2 \mathrm{P}<0.01 \\
0.001<2 \mathrm{P}<0.01\end{array}$ \\
\hline $\begin{array}{c}\text { FEV /VC (D.S.C.G. } \\
\text { /placebo): } \\
\text { Before sabutamol } \\
\text { After salbutamol }\end{array}$ & $\begin{array}{l}\text { N.S. } \\
\text { N.S. }\end{array}$ & $\begin{array}{l}\text { N.S. } \\
\text { N.S. }\end{array}$ & $0.001 \stackrel{\text { N.S. }}{<2 \mathrm{P}}<0.01$ & $\begin{array}{c}0.001<2 \mathrm{P}<0.01 \\
2 \mathrm{P}<0.001\end{array}$ \\
\hline
\end{tabular}

N.S. = Not significant.

taken for each patient, before and after salbutamol, and each value for a D.S.C.G. day was listed alongside the corresponding value for the same control day. A comparison was then made by paired $t$ test. Significant differences were all in favour of D.S.C.G. and the significance increased as the trial progressed. At day 21 the improvement of $\mathrm{FEV}_{1}$ for D.S.C.G. over placebo was highly significant $(2 \mathrm{P}<0.001)$.

A comparison was made between the mean increase in FEV $_{1}$ between days placebo 21 and D.S.C.G. 21 and the mean increase in $F_{1}$ due to salbutamol on day 0 (Table II).

TABLE II-Change in FEV, Due to Salbutamol and D.S.C.G.

\begin{tabular}{|c|c|c|c|}
\hline & \multicolumn{2}{|c|}{ Day 21} & \multirow{2}{*}{$\frac{\text { Day } 0}{\text { Salbutamol }}$} \\
\hline & Before Salbutamol & After Salbutamol & \\
\hline $\begin{array}{l}\text { (1) Mean control FEV } \text { (1.) }_{1} \\
\text { (2) Mean test FEV } \text { (1.) }_{\text {(3) }} \text { Mean difference } 2-1 \text { (1.) } \\
\text { (4) } 3 \text { as percentage of } 1 \\
\text { (5) } 68 \% \text { limits of } 3 \text { (1.) } \\
\text { (6) } 5 \text { as percentage of } 1\end{array}$ & $\begin{array}{l}1.72 \text { (Placebo) } \\
1.88 \text { (D.S.C.G.) } \\
0.16 \\
9 \\
-0.30 \text { to } 0.63 \\
-17 \text { to } 37\end{array}$ & $\begin{array}{l}2.16 \text { (Placebo) } \\
2.33 \text { (D.S.C.G.) } \\
0.17 \\
8 \\
-0.22 \text { to } 0.56 \\
-10 \text { to } 26\end{array}$ & $\begin{array}{l}1.65 \\
2.03 \\
0.38 \\
23 \\
0.01 \text { to } 0.75 \\
1 \text { to } 45\end{array}$ \\
\hline
\end{tabular}

"Control" FEV $_{1}$ is that during placebo on day 21 or before salbutamol on day 0. "Test" FEV ${ }_{1}$ is that during D.S.C.G. on day 21 or after salbutamol on day 0. D.S.C.G. was associated with a rise of $9 \%$ in the mean FEV 1 before salbutamol and an $8 \%$ further rise in the mean FEV $_{1}$ after salbutamol. The mean increase after salbutamol on day 0 was $23 \%$.

The change in FEV 1 was rather variable, as shown in Table II by the $68 \%$ confidence limits of the difference ( \pm 1 S.D.) About $16 \%$ of patients responded very favourably and showed an increase in $\mathrm{FEV}_{1}$ of more than $45 \%$ of the mean control value after salbutamol alone, of more than $37 \%$ after D.S.C.G. alone, and of more than $26 \%$ after D.S.C.G. after salbutamol On the other hand, about $16 \%$ actually showed a fall of greater than 17 and $10 \%$, before and after salbutamol respectively, in association with the administration of D.S.C.G.

No significant improvement of $\mathrm{FEV}_{1}$ was apparent when, instead of comparing the $\mathrm{FEV}_{1}$ changes for the three-week trial periods, a comparison was made of changes in $\mathrm{FEV}_{1}$ over the shorter intervals preceding or after the three days of prednisone. In Table III, the FEV 1 on day 13 was taken as showing the maximal effect of prednisone, and this was compared with the FEV 1 on days 0, 9, and 21. When the D.S.C.G. period is considered alone, the mean $\mathrm{FEV}_{1}$ on day 13 is seen to be significantly greater than on the other three days; the difference between day 13 and day 9 was probably due mainly to the prednisone. However, as shown in Table III, the dif-

TABLE III-Effect of Prednisone on FEV , before Salbutamol

\begin{tabular}{|c|c|c|c|c|c|c|}
\hline & \multicolumn{3}{|c|}{$\begin{array}{l}\text { Mean Increase in FEV } \\
\text { on D.S.C.G. }\end{array}$} & \multicolumn{3}{|c|}{$\begin{array}{l}\text { Mean D.S.C.G.-Placebo } \\
\text { Difference in FEV }\end{array}$} \\
\hline & (1.) & (\%) & Significance & (1.) & $(\%)$ & Significance \\
\hline $\begin{array}{l}\text { Day 13-Day } 0 \\
\text { Day 13-Day } 9 \\
\text { Day 13-Day } 21\end{array}$ & $\begin{array}{l}0.38 \\
0.19 \\
0.13\end{array}$ & $\begin{array}{l}41 \\
14 \\
10\end{array}$ & $\begin{array}{c}2 \mathrm{P}<0.001 \\
2 \mathrm{P}<0.001 \\
0.01<2 \mathrm{P}<0.02\end{array}$ & $\begin{array}{r}0.10 \\
-0.04 \\
-0.06\end{array}$ & $\begin{array}{r}0.04 \\
-0.04 \\
-0.07\end{array}$ & $\begin{array}{l}\text { N.S. } \\
\text { N.S. } \\
\text { N.S. }\end{array}$ \\
\hline
\end{tabular}


ferences in $\mathrm{FEV}_{1}$ over these intervals were not significantly affected by whether the patient received placebo or D.S.C.G. One may conclude that the effect of prednisone was the same whether or not D.S.C.G. was given (day 13-day 9), and that there was no significant difference in the trend of $\mathrm{FEV}_{1}$, during those intervals not so markedly influenced by prednisone (day 13-day 0 and day 13-day 21), between D.S.C.G. and placebo. The interval day 9-day 0 , not at all influenced by prednisone, was tested with the same result.

\section{SYMPTOMS}

The mean daily symptom score was calculated for each patient, each symptom (seven by day and seven by night), each week in each half of the trial, and the placebo-D.S.C.G. difference calculated for corresponding scores; a paired $t$ test was then carried out for each symptom and each week. In every case the advantage lay with D.S.C.G., and in many instances the difference was statistically significant (Table IV). The differences were, however, always small-as shown in Table $V$ in which the six most highly significant differences $(2 P<0.001)$ from Table IV are shown in more detail. The mean "numbers of attacks" in Table V imply that a mean incidence of 14 attacks a week was reduced to 10 attacks a week during the administration of D.S.C.G. The mean placebo-D.S.C.G. difference for the remaining symptoms is $\mathbf{0 . 2 8 6}$, equivalent to a difference of one grade on two days a week.

TABLE IV-Mean Daily Symptom Scores showing Comparison of D.S.C.G. with Placebo

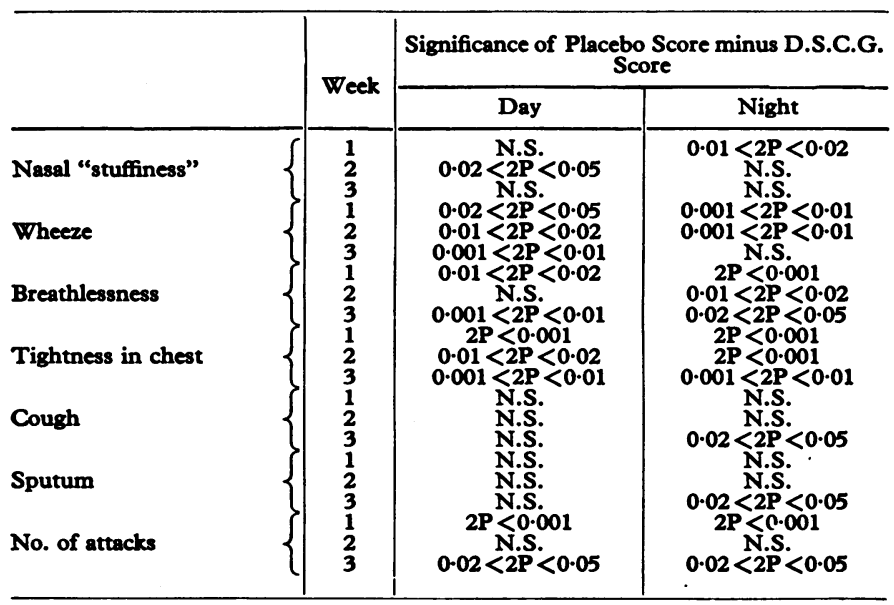

N.S. = Not significant.

TABLE V-Mean Daily Symptom Scores where $2 P<0.001$

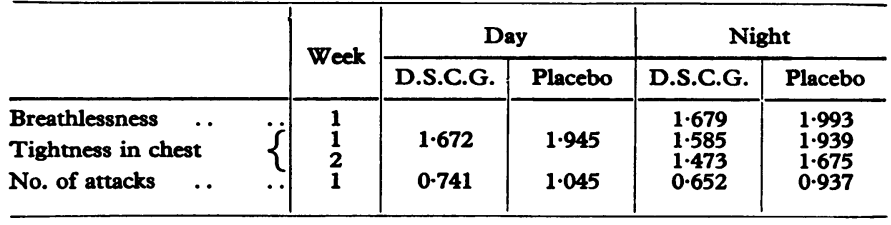

\section{CORRELATION OF SPIROMETRY WITH SYMPTOMS}

Those patients who showed the biggest D.S.C.G.-placebo differences in $\mathrm{FEV}_{1}$ on day 19 and/or day 21, and before and/or after salbutamol, were identified. The criterion by which they were chosen was a D.S.C.G.-placebo difference bigger than the mean of the whole series plus 1 S.D. Similarly, for each recorded symptom, those with a D.S.C.G.-placebo advantage better than the mean plus 1 S.D. were identified; the basis for this selection was the last three days' score minus the first three days' score. Two questions were then asked: (1) Were the FEV improvers and the symptomatic improvers the same people? (2) Were the clinical characteristics of those whose $\mathrm{FEV}_{1}$ improved most on D.S.C.G. different from those of the whole series of 117 patients?

\section{Improvement in $F E V_{1}$ and in Symptoms}

There were 14 symptom categories, seven during the day and seven for the night. In each category the patients showing a good response (as defined above) were listed. For each patient the number of symptom categories in which such a response occurred was then determined. The same procedure was followed for the 32 patients who showed the best response

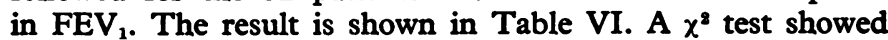

TABLE VI-Distribution of "Best" Symptom Improvement on D.S.C.G.

\begin{tabular}{|c|c|c|c|c|c|c|}
\hline \multirow{2}{*}{$\begin{array}{c}\text { No. of } \\
\text { Symptom Categories } \\
\text { Showing Good } \\
\text { Improvement } \\
(\text { Maximum = 14) }\end{array}$} & \multicolumn{2}{|c|}{$\begin{array}{l}\text { Whole Series } \\
\text { (117 Patients) }\end{array}$} & \multicolumn{4}{|c|}{$\begin{array}{c}\text { FEV } 11 \text { Improvers } \\
\text { (32 Patients) }\end{array}$} \\
\hline & No. of Patients & $\%$ & $\begin{array}{c}\text { Day } \\
19 \text { or } 21\end{array}$ & $\begin{array}{c}\text { Day } \\
19 \text { and } 21 \\
\end{array}$ & Total & $\%$ \\
\hline $\begin{array}{r}0 \\
1 \\
2 \\
3 \\
4 \\
5 \\
6 \\
7 \\
7 \\
8 \\
9 \\
10 \\
11 \\
12 \\
13 \\
14 \\
\end{array}$ & \begin{tabular}{|c|}
48 \\
22 \\
14 \\
13 \\
9 \\
7 \\
2 \\
2 \\
0 \\
1 \\
0 \\
0 \\
0 \\
0 \\
0 \\
1 \\
\end{tabular} & $\begin{array}{r}41 \\
19 \\
12 \\
11 \\
8 \\
6 \\
2 \\
0 \\
1 \\
0 \\
0 \\
0 \\
0 \\
0 \\
1\end{array}$ & $\begin{array}{l}9 \\
7 \\
2 \\
2 \\
3 \\
2 \\
0 \\
0 \\
1 \\
0 \\
0 \\
0 \\
0 \\
0 \\
0\end{array}$ & $\begin{array}{l}\mathbf{5} \\
0 \\
0 \\
0 \\
0 \\
0 \\
1 \\
0 \\
0 \\
0 \\
0 \\
0 \\
0 \\
0 \\
0\end{array}$ & $\begin{array}{r}14 \\
7 \\
2 \\
2 \\
3 \\
2 \\
1 \\
0 \\
1 \\
0 \\
0 \\
0 \\
0 \\
0 \\
0\end{array}$ & $\begin{array}{r}44 \\
22 \\
6 \\
6 \\
9 \\
6 \\
3 \\
0 \\
3 \\
0 \\
0 \\
0 \\
0 \\
0 \\
0\end{array}$ \\
\hline Total & 117 & 101 & 26 & 6 & 32 & 99 \\
\hline
\end{tabular}

no significant difference between the two distributions, indicating that improvement in $\mathrm{FEV}_{1}$ was not associated with either a better or a worse response in symptoms than the average.

\section{Clinical Characteristics of Patients Showing the Best Improvement} in FEV

The 32 patients showing "best" improvement, as previously defined, in FEV due to D.S.C.G. on day 19 or day 21 , or on both days, and before and/or after salbutamol, were compared with the remainder in respect of clinical features by means of appropriate $\chi^{2}$ tests.

Age and sex, separately and combined, showed no association with FEV 1 improvement.

Age of onset, where known and grouped above and below 15 years of age, showed no association with $\mathrm{FEV}_{1}$ improvement.

Duration and frequency of attacks were not associated with FEV 1 response.

Duration of asthma-only 14 patients gave a history of five years or less, giving "expected" numbers too small to test. No association with $\mathrm{FEV}_{1}$ response was obvious.

Eosinophils in blood and sputum, separately and in combination, showed no association.

Personal history of allergy and/or family history of allergy (including asthma) were not associated with the response of FEV $_{1}$ to D.S.C.G.

Seasonal incidence, "warmer" or "colder" or either, was not associated.

Previous treatment with steroids, classified as "never," "when severe," or "regularly," showed no association with the FEV 1 response.

Cough-seventy-two patients gave a history of cough (with or without sputum) between asthmatic attacks. Of the group of 32 patients with "best" responses in $\mathrm{FEV}_{1}, 29$ gave such a history. The difference was highly significant $(2 P<0.001)$. 


\section{Discussion}

\section{SPIROMETRY}

Woolcock and Read (1966) showed that relief of overinflation of the lungs in asthmatic patients may occur without significant change in $F E V_{1}$. This observation provides an explanation of how symptomatic relief may sometimes occur without an increase in FEV . As Tocker and O'Donnell (1972) have shown, however, this phenomenon is uncommon. We believe that it cannot be invoked whenever a supposed remedy for asthma fails to increase the $\mathrm{FEV}_{1}$ and that, as with bronchodilator amines and steroids, an effective drug should induce in most cases a clearly demonstrable effect on the forced expiratory spirogram. This trial provides good evidence that D.S.C.G. given for three weeks to an unselected series of patients with moderately severe bronchial asthma significantly increased $F_{1}$, VC, and $F E V_{1} / V C$ ratio, and is the first to have shown such a highly significant mean change in $F_{1} V_{1}$ in adult patients. The difference between D.S.C.G. and the inactive preparation increased as the trial progressed (Table I). This could have been due to a cumulative effect of D.S.C.G., and if so the difference might have become bigger had the trial lasted longer. Alternatively, a carry-over effect in the patients who received placebo second could have biased the result against placebo.

The mean increase in $\mathrm{FEV}_{1}$ ascribable to D.S.C.G. was, however, less than $10 \%$. The immediate increase of $23 \%$ after salbutamol on day 0 provides an indication of the potential for prompt improvement in these patients. A mean value conceals high and low values, and as shown in Table II the $\mathrm{FEV}_{1}$ increased in a few patients on D.S.C.G. almost as much as after salbutamol. However, when assessing the overall improvement by comparing the effect of D.S.C.G. with the acute and more transient benefit after salbutamol, the mean increase in $\mathrm{FEV}_{1}$ provides a more reliable guide.

The patients showing the best responses in $\mathrm{FEV}_{1}$ did not show a symptomatic improvement better than the remainder (Table VI). This supported the view that the benefit due to D.S.C.G. was small. While it may be argued that symptoms may genuinely improve without change in $\mathrm{FEV}_{1}$, it is extremely unlikely that a major increase in FEV 1 would not be accompanied by symptomatic relief.

\section{EFFECT OF PREDNISONE}

Much of the improvement from the high dosage of prednisone (30 mg daily) used in this trial would be expected to occur within 72 hours except in patients recovering from a severe exacerbation of asthma. The chief aim of the administration of prednisone was to provide an indication of the potential capacity for improvement in the patients under study. The degree of improvement on the prednisone would indicate the best that could be hoped for from D.S.C.G. To achieve maximum cooperation from the eight centres engaged in this trial it had to be completed within a seven-week period before Easter. The administration of prednisone had to be limited to three days in order not to interfere with the primary task of comparing D.S.C.G. and placebo. As expected, the mean FEV $_{1}$ during the D.S.C.G. period was greatest on day 13 after the three days of prednisone. By day 21 the mean $\mathrm{FEV}_{1}$ for those on D.S.C.G. was $10 \%$ less than on day 13 . This was an improvement on the $\mathrm{FEV}_{1}$ at day 9 on D.S.C.G. but before the prednisone (Table III).

In spite of the improvement in $\mathrm{FEV}_{1}$ at day 21 for those on D.S.C.G. there was no significant difference between the maximum value for $\mathrm{FEV}_{1}$ on day 13 after the prednisone and the FEV 1 at the 9-day or 21-day stages of the trial whether the patient was on D.S.C.G. or placebo (Table III). This confirmed our conclusion that the significant improvement of FEV $_{1}$ on D.S.C.G. was not a large one.
SYMPTOMS

The trial provided convincing evidence of symptomatic improvement due to D.S.C.G. (Table IV) but, again, the mean improvement noted was small (Table V). As in the case of spirometric measurements it is necessary to consider to what extent mean differences may conceal genuine and substantial improvement in a small number of patients. So far as symptoms are concerned, detailed analysis of this aspect is as likely to mislead as to instruct; the scoring of symptoms is entirely subjective, and as has been shown (Table VI) those patients who reported the biggest symptomatic improvement did not have the biggest increase in $\mathrm{FEV}_{1}$. It would thus be hazardous to suppose, and impossible to prove, that the extremes of response, both good and bad, represented more than random scatter.

Table VI was compiled from the most significant placeboD.S.C.G. differences. A drug which reduces the mean number of attacks from 14 to 10 a week, and makes a difference in other symptoms of from moderate to mild or intolerable to severe on two days a week may certainly have a place in the treatment of asthma, but it can hardly be regarded as impressive.

\section{SELECTION OF PATIENTS FOR TREATMENT}

It would be helpful in practice to be able to identify those patients who are likely to show good responses after D.S.C.G. We have been unable to identify any clinical characteristic by which a good response may be predicted, save one. This was a history of cough, given much more frequently by those who responded better to D.S.C.G. The chosen criterion of response was exceeded by $44 \%$ of those who gave such a history, and by less than $7 \%$ of those who did not.

The criterion used for "cough" was similar to that adopted for chronic bronchitis by the Medical Research Council (1965). It is, however, difficult to say exactly what it means when applied to patients with chronic asthma. Cough is a common symptom of the asthmatic attack, and in many patients it is a somewhat arbitrary exercise to define the absence of an attack. There have been previous reports of favourable responses to D.S.C.G. in patients with a chronic cough (Cayley, 1970; Marshall and Birtwistle, 1970) but the explanation is at present wholly conjectural.

\section{Comment}

In this trial D.S.C.G. produced evidence of symptomatic and functional improvement in a group of unselected adult asthmatic patients. The results are less striking than some optimistic assessments-for example, Howell and Altounyan, 1967made previously on the basis of controlled trials in adults, or the subjective clinical impressions on which current opinion of this drug still widely rests. The present results tend rather to support the assessment of Grant et al. (1967).

Grant (1968) pointed out that the conclusions to be drawn from trials of D.S.C.G. greatly depend on the importance attached to $F E V_{1}$. In the present trial neither $F E V_{1}$ nor symptoms showed striking improvement due to the drug. Another possible source of discrepancy lies in the selection of patients; Howell and Altounyan (1967) apparently selected their 10 patients with "allergic bronchial asthma" solely on the basis of eosinophilia of the sputum. Many patients in the present series could have been selected on this basis, yet neither this nor other stigmata of allergy were associated with a better-than-average response to D.S.C.G.

The contrast between the effects of D.S.C.G. in bronchial provocation studies (Pepys et al., 1968) and in the treatment of clinical asthma raises an important question concerning their relation in most patients. 
Participants in the trial: G. S. Kellaway, Auckland (Convenor); T. Gebbie, Wellington; A. C. Hayton, New Plymouth; P. E. Holst, Dunedin; A. R. Kirk, Nelson; M. Kirk, Palmerston North; J. A. McLeod, Christchurch; T. V. O'Donnell, Dunedin; J. J. O'Hagan, Invercargill; and R. G. P. Rothwell, Hamilton.

\section{References}

Altounyan, R. E. C. (1968). Acta Allergica, 22, 487

Altounyan, R. E. C., and Howell, J. B. L. (1969). Respiration, 26, Suppl. No 131 .

Bernstein, L., et al. (1971). Journal of Allergy, 47, 95.
Cayley, F. E. (1970). Disodium Cromoglycate in Allergic Airways Disease, p. 44. London, Butterworths.

Cotes, J. E. (1966). I.L.O. Occupational Safety and Health Series, No. 6. Gianoutsos, P., and O'Donnell, T. V. (1969). New Zealand Medical fournal, 70,311.

Grant, I. W. B. (1968). Lancet, 2, 282.

Grant, I. W. B., Channell, S., and Drever, J. C. (1967). Lancet, 2, 673.

Howell, J. B. L., and Altounyan, R. E. C. (1967). Lancet, 2, 539

Kennedy, M. C. S. (1967). Lancet, $2,838$.

Marshall, J. S., and Birtwistle, I. H. (1970). Disodium Cromoglycate in Allergic Airways Disease, p. 173. London, Butterworths.

Medical Research Council (1965). Lancet, 1, 776.

Pepys, J., Chan, M., Hargreave, F. E., and McCarthy, D. S. (1968). Lancet, 2, 134 .

Read, J., and Rebuck, A. S. (1969). Medical fournal of Australia, 1, 566. Tocker, D., and O'Donnell, T. V. (1972). New Zealand Medical fournal. In

Woolcock, A. J., and Read, J. (1966). American fournal of Medicine, 41, 259

\title{
Effects of Four Commonly-used Tranquillizers on Low- speed Driving Performance Tests
}

\author{
T. A. BETTS, A. B. CLAYTON, G. M. MACKAY
}

British Medical fournal, 1972, 4, 580-584

\begin{abstract}
Summary
A double-blind controlled comparison of four commonlyused tranquillizing drugs (haloperidol, amylobarbitone sodium, chlordiazepoxide, and trifluoperazine) against placebo was made in their effects on the performance of volunteers during three low speed vehicle-handling tests. The drugs (with the exception of haloperidol) significantly altered driving behaviour though they did not seem to interact significantly with alcohol. There is, therefore, a strong possibility that such drugs will similarly alter driving performance in patients taking them for therapeutic purposes. Since, as these experiments also show, those affected may be subjectively unaware of it, and routine clinical screening is not sensitive enough to detect them, physicians should warn patients of the probability that their driving performance will be affected by such drugs, particularly during the first few days that they are taken.
\end{abstract}

\section{Introduction}

Road accidents are a leading cause of death and morbidity, particularly in young people. Alcohol is directly involved in many of these accidents, and there is growing concern that the large amount of psychotropic medication currently prescribed in the Western hemisphere may also be involved. Several authors have recently reviewed the large amount of literature that reflects the growing interest in this problem (Havard, 1970; Kibrick and Smart, 1970; Waller, 1971; Milner, 1972), though evaluation of the effect of psychotropic drugs on driving performance is much more difficult and has many more methodological problems than studying the effect of alcohol on driving.

This is largely due to the unique pharmacological properties of alcohol. Unlike alcohol, however, the absorption of psycho-

\section{University Department of Psychiatry, Queen Elizabeth Hospital, Birmingham}

T. A. BETTS, M.B., D.P.M., Senior Lecturer in Psychiatry

Department of Transportation and Environmental Planning, The University, Birmingham

A. B. CLAYTON, B.SC, PH.D., Senior Research Associate

G. M. MACKAY, PH.D., M.I.C.E., Senior Research Fellow tropic drugs may be erratic, their metabolism is often complex (the effects of a drug may be difficult to distinguish from those of its related metabolites), and excretion is slow-indeed a patient may still be excreting the drug in the urine several weeks after he has taken his last dose. Blood levels of the drug may have little relation to drug effect, and may not correlate with urine levels of the drug. Dose response relations are more complex than those of alcohol, and the amount of idiosyncratic response or individual variation in response is probably much greater than with alcohol. There is a strong placebo element in drug response.

Psychotropic medication is taken by patients suffering from emotional symptoms or illnesses (which have their own complex effects on performance), and the medication has to be taken regularly. It is unrealistic, therefore, to study the effects of a single dose of a drug on driving performance (as can be done legitimately with alcohol). The use of normal subjects in such experiments also has a slightly limited value.

The direct causal involvement of drugs in road accidents has been examined by determining whether psychotropic drugs were present in the body tissues, blood, or urine of drivers killed or injured in road accidents or involved in traffic violations (reviewed by Havard, 1970). However, no properly controlled study of psychotropic drugs in accident situations has been carried out to compare with the classic study of Borkenstein et al. (1964) on the involvement of alcohol in road accidents, and in the present state of the art we doubt if it could be.

Most studies of the interaction between psychotropic drugs and driving behaviour have been in the laboratory, mostly involving driving simulators (devices of varying complexity in which a number of skills resembling driving can be tested simultaneously). Unfortunately, a simulator needs to be extremely sophisticated to match the demands of an actual driving situation. In addition the attitude and "set" of a subject "driving" in a simulator are likely to be different from his attitude to real driving. Different models (each with their own method of measurement) have been used in the various studies undertaken, and replication experiments have not been done.

In many simulator studies little allowance has been made for practice effects and little pretest training has usually been given. Sometimes sufficient time has not been allowed for absorption and metabolism of the drug before testing.

Most experimenters have used single doses or once repeated doses of the drug under test though some chronic experiments have been done with meprobamate (Kelly et al., 1958a, 1958b).

The results of many simulator studies are now partly irrele- 